\title{
Review
}

\section{Psychrophilic enzymes: molecular basis of cold adaptation}

\section{G. Feller* and C. Gerday}

Laboratory of Biochemistry, Institute of Chemistry B6, University of Liège, B-4000 Liège Sart Tilman (Belgium), Fax + 324366 3364, e-mail: gfeller@ulg.ac.be

\begin{abstract}
Psychrophilic organisms have successfully colonized polar and alpine regions and are able to grow efficiently at sub-zero temperatures. At the enzymatic level, such organisms have to cope with the reduction of chemical reaction rates induced by low temperatures in order to maintain adequate metabolic fluxes. Thermal compensation in cold-adapted enzymes is reached through improved turnover number and catalytic efficiency. This optimization of the catalytic parameters can originate from a highly flexible structure which
\end{abstract}

provides enhanced abilities to undergo conformational changes during catalysis. Thermal instability of coldadapted enzymes is therefore regarded as a consequence of their conformational flexibility. A survey of the psychrophilic enzymes studied so far reveals only minor alterations of the primary structure when compared to mesophilic or thermophilic homologues. However, all known structural factors and weak interactions involved in protein stability are either reduced in number or modified in order to increase their flexibility.

Key words. Psychrophiles; extremophiles; cold adaptation; microbial proteins; protein stability; weak interactions; Antarctic.

Psychrophiles live at the lowest temperatures which allow the development of living organisms. These extremophilic organisms, either prokaryotic or eukaryotic, represent a major class of the living world if we consider the vast extent of permanently cold environments on Earth, such as polar and alpine regions or deep-sea waters. The successful colonization of such severe ecological niches by psychrophiles, their diversity and abundance are now well recognized.

The lower temperature limit of life is commonly defined as the freezing point of cellular water. Although apparently simple by definition, this limit can drop significantly below $0{ }^{\circ} \mathrm{C}$, the freezing point of pure water. For instance, the freezing point of a typical marine teleost ranges between -0.5 and $-0.9{ }^{\circ} \mathrm{C}$. Sodium chloride is

* Corresponding author. responsible for about $85 \%$ of the freezing point depression, and the remaining $15 \%$ is due to other small solutes. Synthesis of antifreeze glycoproteins and peptides can further depress the freezing point of body fluids or cellular water. These proteins lower the freezing point by a noncolligative mechanism without altering the melting point significantly, and are therefore also referred to as thermal hysteresis proteins [1, 2]. They were first discovered in the blood sera of Antarctic fish living perennially at about $-1.9^{\circ} \mathrm{C}$, but have been now reported in many organisms including plants, insects, fungi and bacteria [3-5]. Levels of thermal hysteresis activity generally range from 0.1 to $0.3{ }^{\circ} \mathrm{C}$ in bacteria, from 0.2 to $0.5^{\circ} \mathrm{C}$ in plants, from 0.7 to $1.5^{\circ} \mathrm{C}$ in fish and from 3 to $6{ }^{\circ} \mathrm{C}$ in insects. Besides the synthesis of cryoprotectants which lead to freeze avoidance, several organisms have developed mechanisms of freeze tolerance, involving drastic metabolic modifica- 
tions during frost hardening, and resistance to membrane damage, solute concentration and dehydration accompanying ice crystallization [6]. As discussed by Russell [7, 8], there are no substantiated reports of microbial growth at temperatures below $-12{ }^{\circ} \mathrm{C}$. However, the endolithic microbial communities described in Antarctic dry valleys also underline the difficulty in defining the lower thermal limit of life. These microorganisms are able to grow between the crystals of porous rocks and endure temperatures between 0 and $-15^{\circ} \mathrm{C}$ in the summer, but survive exposure to about $-60{ }^{\circ} \mathrm{C}$ during the winter [9].

As can be anticipated from these selected examples, molecular adaptation to cold includes a vast array of biochemical adjustments at the level of single molecules (enzyme kinetics, synthesis of specialized molecules etc.) or of supramolecular and subcellular edifices (regulation of membrane fluidity, ion channels, polymerization/depolymerization of tubulins etc.) and finally of the whole organism physiology (biochemical pathways, frost hardening, seasonal dormancy etc.). An excellent survey of the biophysical implications of life at low temperatures can be found in [6]. Some other biochemical and physiological aspects have also been reviewed [10-14]. The emerging interest in cold shock proteins should also provide new insights for cold adaptation in the future [15-19]. After a brief review of psychrophily, we shall concentrate here mainly on the problem of enzyme kinetics at low temperatures, and on the molecular adaptations of enzymes isolated from psychrophilic organisms.

\section{Psychrophily: an evolving concept}

In a recent analysis of the crystal structure of D-glyceraldehyde-3-phosphate dehydrogenase isolated from psychrophiles, mesophiles and thermophiles, the enzyme from the lobster Homarus americanus (which lives at 20 ${ }^{\circ} \mathrm{C}$ ) was used as the psychrophilic reference [20]. Although the conclusions of this interesting work are not affected by such a taxonomical error, it is important to reconsider the definition of psychrophily in order to avoid future confusion. The first mention of the term 'psychrophile' was apparently made by Schmidt-Nielsen in 1902 [21] for the description of bacteria capable of growing at $0{ }^{\circ} \mathrm{C}$. There are in fact no formal reasons to restrict the term psychrophile to bacteria, or to prokaryotes. Various species of yeast, algae [22, 23], insect [24], fish [25] and probably plant can be referred to as psychrophiles if they continuously experience low temperatures, for example below an arbitrary limit of $5^{\circ} \mathrm{C}$.

Among microorganisms, which can grow over a temperature span of $20^{\circ} \mathrm{C}$ or more, it is necessary to distinguish psychrophiles from psychrotrophs because of differences in the ecological distribution and biochemical adapta-

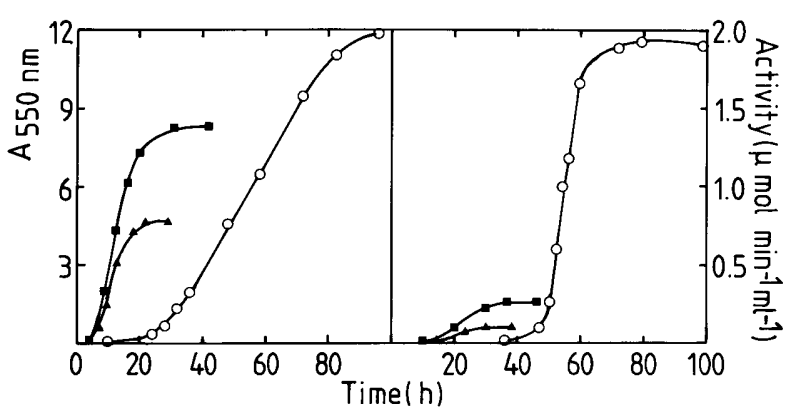

Figure 1. Growth of Alteromonas haloplanctis A23 in rich medium (left panel) and $\alpha$-amylase secretion in the culture supernatant (right panel) at $4{ }^{\circ} \mathrm{C}(\mathrm{O}), 18{ }^{\circ} \mathrm{C}(\boldsymbol{\square})$ and $25^{\circ} \mathrm{C}(\boldsymbol{\Delta})$. Note the inhibition of the cell density (but not of growth rates) and of exoenzyme production as the temperature is raised. (Reprinted with permission from: Feller G., Narinx E., Arpigny J. L., Zekhnini Z., Swings J. and Gerday C. (1994) Temperature dependence of growth, enzyme secretion and activity of psychrophilic antarctic bacteria. Appl. Microbiol. Biotechnol. 41: 477-479, (c) 1997 Springer Verlag, Heidelberg).

tions of both groups [7, 8]. The widely accepted definition by Morita [21] proposes that psychrophiles include organisms having optimum growth temperatures $<15$ ${ }^{\circ} \mathrm{C}$ and upper cardinal temperatures around $20^{\circ} \mathrm{C}$, whereas psychrotrophs have optimum growth temperatures $>15^{\circ} \mathrm{C}$ and upper cardinal temperatures $>20{ }^{\circ} \mathrm{C}$, although they are able to multiply close to $0^{\circ} \mathrm{C}$. We can also add that the term 'psychrotolerant' should be used for mesophilic species that are able to acclimatize at low temperatures. It is worth mentioning that growth rates are inaccurate as a sole criterion to determine the optimal growth temperature. This is clearly illustrated by Antarctic marine bacteria permanently living at $0 \pm 2{ }^{\circ} \mathrm{C}$ (fig. 1). Some of these bacteria grow faster at 20 to 25 ${ }^{\circ} \mathrm{C}$ but their physiological state is drastically impaired at this temperature, as judged by the reduced viable counts and the low (sometimes abolished) exoenzyme production [26]. In addition, substrate requirement, in terms of type and quantity of organic nutrients, strongly influences bacterial growth in the cold $[27,28]$, which makes comparison of generation times somewhat difficult. Keeping these restrictions in mind, Morita's definitions remain perfectly valid providing an optimal physiological temperature is defined. This concept has been successfully explored during the study of psychrotrophic Pseudomonas [29-32]. For these species a critical temperature, close to the break point of an Arrhenius plot of growth rates, separates two domains of temperature characterized by the rates of exoenzymes production, the rates of protein accumulation and the permeability of the outer membrane. The authors proposed that a new cardinal temperature, Tao (temperature of optimal activity) as opposed to the temperature of optimal 


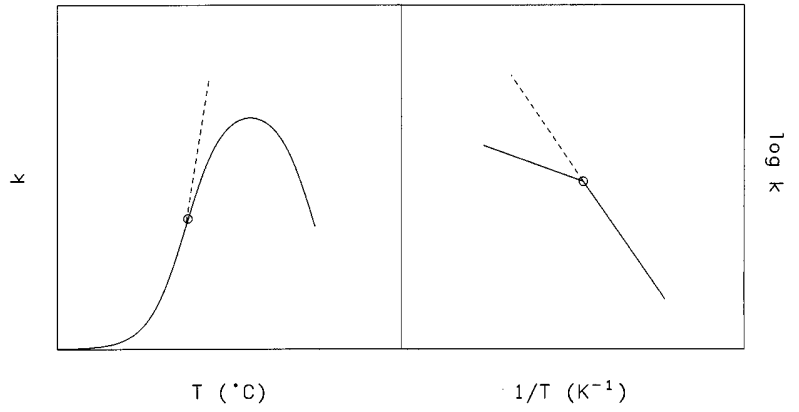

Figure 2. Effect of temperature on the reaction rate $k$ (left panel) for an enzyme-catalysed reaction (-) and for an uncatalysed reaction (---). The inflexion point $(\bigcirc)$ on the enzyme-catalysed reaction curve corresponds to the break point of the corresponding Ahrrenius plot (right panel).

growth rate, might be useful for further analyses of cold-adapted microorganisms. Inevitably, there is a continuity in the distribution of psychrophile, psychrotroph and psychrotolerant species. Nevertheless, the selection of a true psychrophile (or possibly an extreme psychrophile) for fundamental research or for biotechnological use, ensures that time and intensity of the selective pressure have favoured highly optimized molecular adaptations.

\section{Thermal dependence of biological rate constants}

In view of the growing interest in the field, it seems useful to comment on some basic principles as well as technical aspects of the thermodependence of biological activities.

The reaction rate $(k)$ of a non-catalysed reaction $\mathrm{S} \rightleftharpoons \mathrm{P}$ depends exponentially on temperature according to the relation:

$$
k=\frac{\kappa \mathrm{K}_{\mathrm{B}}}{\mathrm{h}} e^{-\Delta G^{*} / \mathrm{RT}}
$$

where $\kappa$ is the transmission coefficient; $\mathrm{K}_{\mathrm{B}}$ the Bolzmann constant $\left(1.38 \times 10^{-23} \mathrm{~J} \mathrm{~K}^{-1}\right)$; h the Planck constant $\left(6.63 \times 10^{-34} \mathrm{~J} \mathrm{~s}^{-1}\right) ; \mathrm{R}$ the gas constant $(8.31 \mathrm{~J}$ $\mathrm{K}^{-1} \mathrm{~mol}^{-1}$ ); $\mathrm{T}$ the temperature in degrees Kelvin and $\Delta G^{*}$ the activation free energy.

In theory, a monotonous exponential dependence of the rate constant $k$ with temperature will be observed (fig. 2) up to the boiling point of the reaction medium or until S or P degrades at the highest temperatures. Only thermophiles have to cope with the problem of thermolabile substrates and products, and seem to speed up some sensible reaction steps to avoid degradation of the components, as shown by the phosphoribosyl anthranilate isomerase from Thermotoga maritima [33]. At the other end of the biological temperature scale, rate constants are not nil at $0{ }^{\circ} \mathrm{C}$ (in eq. (1), $\mathrm{T}$ is in degrees Kelvin, not in degree Celsius) but are drastically reduced. In fact, sub-zero temperatures are commonly used in cryoenzymology to slow down the formation of transient catalytic intermediates.

Due to the polypeptidic nature of enzyme catalysts in biological systems, the exponential thermal dependence of $k$ is recorded over a limited range of temperatures. Increasing the temperature above the physiological temperature results in reversible alterations of the protein conformation (from the native active state $\mathrm{N}$ to the unfolded inactive state $U$ ) which are usually followed by irreversible denaturation (to the state I)

$$
\mathrm{N} \underset{\mathrm{k}_{-1}}{\stackrel{\mathrm{k}_{1}}{\rightleftharpoons}} \mathrm{U} \stackrel{\mathrm{k}_{2}}{\rightarrow} \mathrm{I}
$$

Note that three rate constants are involved in this simple case. The situation can occasionally become more complicated and require additional rate constants. In addition, the individual kinetic rate constants contributing to $k$ of an enzyme-catalysed reaction can have widely different temperature dependencies. The net result of substracting active species to the system is the occurrence of an inflexion point in the exponential increase of $k$ (fig. 2). Further, when the denaturation rate becomes pre-eminent, activity decreases after a maximum, giving rise to the classical bell-shaped thermal dependence of activity (or cell growth). As a rule of thumb, the exponential part of the curve reflects the genuine thermal dependence of chemical reaction rates; the part of the curve between the inflexion point and the top region arises from the balance between heatinduced activation and unfolding rates; whereas the sharp decrease corresponds to the irreversible $\mathrm{U} \rightarrow \mathrm{I}$ conversion. Accordingly, it should be understood that the maximum of the curve (the so-called apparent optimal temperature of activity) has little, if any, biochemical significance because it results from so many unrelated parameters. In practice, this maximum is also influenced by the concentration of enzyme, substrate or cofactor, by the ionic strength, by the $\mathrm{pH}$ and even by the time and the mode of kinetic measurement (stopflow determination initiated by enzyme addition can provide the rate constant of the native state at a given temperature, whereas preincubation of the enzyme at this temperature and initiation by substrate addition will give the rate constant after the equilibrium $\mathrm{N} \rightleftharpoons \mathrm{U}$ is reached). Nevertheless, comparison of such curves from psychrophilic, mesophilic and thermophilic enzymes usually shows a strong displacement of the apparent optimum in relation to the environmental temperature of the parent organism, as well as substantial activity at low temperatures in the case of psychrophilic enzymes.

Thermal activation of biological rate constants is often illustrated in the form of Arrhenius plots. These are a 
graphical method to transform an exponential function into a linear one, and are primarily used to calculate the Arrhenius activation energy (Ea) and to estimate the free energy of activation $\Delta G^{*}$, i.e. the true energy barrier of the reaction. Note that $\Delta G^{*}$ can be obtained only if the number of molecules present in the system is accurately known. Plotting $\log k=\mathrm{f}(1 / \mathrm{T})$ results in a straight line with a slope $-\mathrm{Ea} / 2.303 \mathrm{R}$ in the exponential portion of the activity curve. The thermodynamic activation parameters can then be calculated according to the following equations [34]:

$\Delta G^{*}=\Delta H^{*}-\mathrm{T} \Delta S^{*}$

$\Delta H^{*}=\mathrm{Ea}-\mathrm{RT}$

$\Delta S^{*}=2.303 \mathrm{R}(\log k-10.753-\log \mathrm{T}+\mathrm{Ea} / 2.303 \mathrm{RT})$

For any quantitative significance to be attached to such calculations, the temperature must be controlled to $0.1^{\circ} \mathrm{C}$ and the uncertainty in $k$ remain below $5 \%$. When measuring biological rate constants as a function of temperature, a break in Arrhenius plots is invariably observed. This break corresponds to the inflexion point shown in figure 2, that is when any phenomenon starts competing with the exponential increase of $k$. Because of the complex nature of this transition, as stated above, an Arrhenius plot can present several break points (e.g. in the case of membrane-embedded enzymes subjected to the lipid bilayer phase transition) or it can be sharply bended if several events interfere simultaneously [35]. It is therefore extremely hazardous to relate the break point temperature to any common biological property because it is an intrinsic property of a given system, either a molecule or a growing organism. Nonetheless, Arrhenius plots constructed with growth rates or enzyme rate constants of psychrophiles generally display a break point temperature significantly lower than that recorded for mesophiles and a fortiori for thermophiles, which reflects the thermal sensitivity of cold-adapted organisms and of their proteinic components.

\section{Catalysis at low temperatures: a thermodynamic challenge}

According to eq. (1), any decrease in temperature causes an exponential decrease of the reaction rate, the magnitude of which depends of $\Delta G^{*}$. Accordingly, most biological systems, including the single biochemical reaction, display a reaction rate 2 to 3 times lower when the temperature is decreased by $10{ }^{\circ} \mathrm{C}\left(\mathrm{Q}_{10}=2\right.$ to 3$)$. As a consequence, the activity of a mesophilic enzyme is between 16 and 80 times lower when the reaction temperature is shifted from $37^{\circ} \mathrm{C}$ to $0{ }^{\circ} \mathrm{C}\left(\approx 2^{4}-3^{4}\right)$. Thus, it is surprising that metabolic rates of Antarctic fish are only slighly lower than those of temperate water species
[36] and that the generation time of psychrophilic bacteria near $0{ }^{\circ} \mathrm{C}$ are of the same order as those of mesophilic microorganisms at $37{ }^{\circ} \mathrm{C}[21,26,37]$. Clearly, psychrophilic organisms have found mechanisms of temperature compensation in order to cope with the reduction of chemical reaction rates inherent to low temperatures.

\section{Some possible strategies}

Synthesizing more enzymes or synthesizing cold-efficient enzymes are two possible ways to adapt. Adjustment in enzyme concentration has been reported in rare cases during acclimation or acclimatization of ectotherms. For instance, higher levels of cardiac LDH-B and of mRNA for this enzyme have been detected in cold-adapted populations of the teleost Fundulus heteroclitus when compared to warm-adapted populations [38, 39]. It can be easily understood that such a strategy is energetically expensive and cannot be extended to the whole organism. Species undergoing migrations along a sharp thermal gradient, or occurring over widely different thermal habitats, can also express specific isozymes kinetically adapted to a given environment (see [14] for review). This strategy is of course restricted to polyploid species, or when multicopies of genes are available, but at the molecular level draws the distinction between psychrotolerant (adaptation of key functions) and psychrophilic species (adaptation of all functions).

Another way to maintain sustainable activity at low temperature is to possess enzymes characterized by temperature-independent reaction rates. This is the case of perfectly evolved enzymes: their reaction rate occurs almost as fast as the protein and substrate encounter one another, and is said to be diffusion controlled. The activation energy $\Delta G^{*}$ tends to zero and therefore the exponential term in eq. (1) tends to 1 . It follows that the rate of these very fast reactions is virtually independent of temperature. However such enzymes are relatively rare: typical examples are carbonic anhydrase, acetylcholinesterase or triosephosphate isomerase. Perfectly evolved enzymes could be extremely useful to probe the various hypotheses related to enzyme adaptation because, apparently, they do not need to be adapted to low temperatures from a kinetic standpoint.

The most striking adaptational character of psychrophilic enzymes is certainly their high specific activity or turnover number $k_{\text {cat }}$. Indeed, improving $k_{\text {cat }}$ offsets the effect of low temperatures on catalytic rate and therefore provides adequate raw metabolic activity to the growing organism. This strategy is not specific to psychrophilic organisms but is also observed when enzymes from warm-blooded animals are compared to homologues from ectothermic species [11, 14]. Adaptation in $k_{c a t}$ values of psychrophilic enzymes represent an 
extreme trend of the thermal compensation strategies. However, $k_{\text {cat }}$ of an elementary enzymatic reaction reflects the catalytic potential of enzyme-substrate complexes at saturating substrate concentrations. Strictly speaking, the catalytic efficiency is best described by the $k_{c a t} / K_{m}$ ratio, underlining that substrate binding events have to be taken into consideration when dealing with temperature adaptation of the catalytic function. Substrate binding is an especially temperature-sensitive step because both the binding site geometry and interactions between binding site and ligand are governed by weak interactions having specific and sometimes opposite temperature dependencies. Hydrophobic interactions form endothermically and are weakened by a decrease in temperature. By contrast, interactions of electrostatic nature (ion pairs, hydrogen bonds, Van der Waals interactions) form exothermically and are stabilized at low temperatures. It is worth mentioning that $K_{m}$ values for homologues of eukaryotic enzymes are similar in differently adapted species at their normal body temperature [14], which reflects a fine tuning of the interactions involved in substrate binding.

As mentioned, $k_{\text {cat }} / K_{m}$ is generally a better indication of catalytic evolution than $k_{c a t}$ alone, especially in the case of regulatory intracellular enzymes that catalyse their reaction at substrate concentrations close to the $K_{m}$ value. On the other hand, we could expect optimization of $k_{c a t}$ to be the only relevant parameter for enzymes usually buried in huge amount of substrate, such as digestive enzymes or enzymes secreted by microorganisms growing within their substrate sources. Conversely, exoenzymes from marine or freshwater microorganisms should have highly optimized $K_{m}$ values if they are secreted in the substrate-poor liquid medium, unless the microorganism adsorbs on or within organic debris. These extreme examples show that it is often difficult to decide which parameter is to be optimized in the context of cold adaptation. Care should also be taken when determining thermal dependence of $K_{m}$ by using small chromogenic substrates instead of the natural macromolecular substrates like those of hydrolases and depolymerases. Small synthetic substrates are very easy to handle and give more reproducible results but may have quite distinct binding modes. As a result, large differences in temperature dependence of $K_{m}$ for both substrates can be recorded, as examplified by $\alpha$-amylase in table 1 . Detailed kinetic analyses are still lacking for the vast majority of psychrophilic enzymes isolated so far. Nevertheless, comparison of the available data (most of them obtained using chromogenic substrates) indeed reveals a tendency to optimize $k_{\text {cat }} /$ $K_{m}$ at the temperature of the habitat (table 1), as shown by digestive enzymes from antarctic or arctic fish [4043] and by exoenzymes from antarctic microorganisms $[44,45]$.

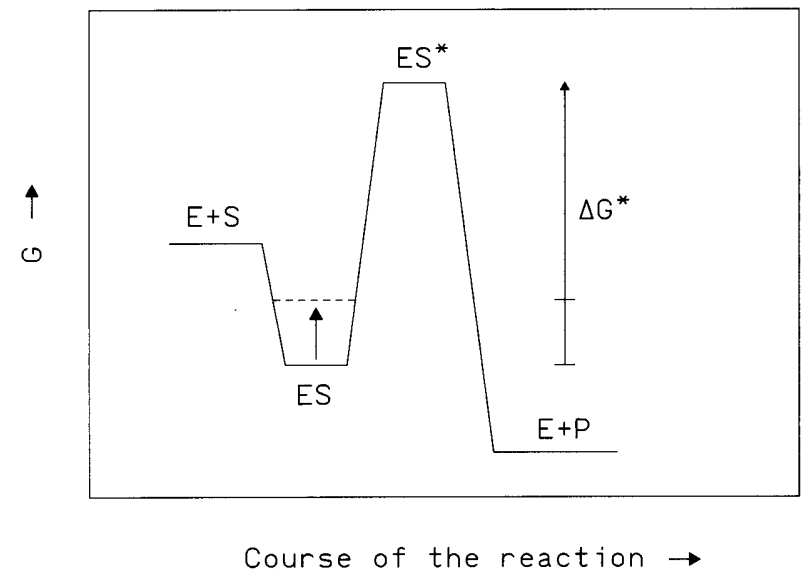

Figure 3. Reaction profile for an enzyme-catalysed reaction with Gibbs energy changes under saturating substrate concentration. The enzyme-substrate complex ES has a lower energy than the individual enzyme $\mathrm{E}$ and substrate $\mathrm{S}$. The activation energy of the reaction $\left(\Delta G^{*}\right)$ is the difference in energy between ES and the transition state ES*. Schematically, weak substrate binding (dashed) decreases the activation energy and thereby increases the reaction rate (note that stabilizing ES* would have the same effect).

\section{Optimization of the catalytic effectiveness}

As can be inferred from eq. (1), increasing the rate constant at a given temperature conceptually corresponds to reduce the energy barrier, that is the magnitude of $\Delta G^{*}$ (fig. 3). In a pioneering work [34] it has been shown that enzymes from cold-adapted species indeed display reduced $\Delta G^{*}$ values, and that the contribution of enthalpic and entropic energies to $\Delta G^{*}$ may reflect adaptations to the low temperature environment in which these enzymes function. As shown in table 2, the low enthalpies of activation $\Delta H^{*}$ characteristic of cold- adapted enzymes render chemical reactions relatively temperature-independent. Moreover, reducing the entropy of the enzyme-substrate complex or keeping entropy increase to a minimum appears to minimize the amounts of heat present in the medium to activate the enzyme-substrate complex. For instance, weakening ES or ES* binding strength, and therefore reducing the magnitude of the conformational adjustments implicated, contributes to lower $\Delta G^{*}$ (fig. 3).

\section{Kinetic and thermodynamic optimization}

There is apparently an evolutionary pressure on $K_{m}$ to increase, or to bind substrates weakly in order to maximize the overall reaction rate [46]. This is illustrated in figure 3, which shows that strong substrate binding leads to a thermodynamic pit during the formation of the enzyme-substrate complex ES, before the transition 
Table 1. Kinetic parameters of psychrophilic enzymes from microorganisms and fish as compared to mesophilic and homeothermic homologues.

\begin{tabular}{|c|c|c|c|c|c|}
\hline Enzyme (substrate) & $\mathrm{T}\left({ }^{\circ} \mathrm{C}\right)$ & $k_{\text {cat }}$ & $K_{m}$ & $k_{\text {cat }} / K_{m}$ & ref. \\
\hline \multicolumn{6}{|l|}{$\alpha$-Amylase (EPS) } \\
\hline \multirow[t]{2}{*}{ A. haloplanctis (Antarctic bacteria) } & 4 & $233 \mathrm{~s}^{-1}$ & $820 \mu \mathrm{M}$ & $0.28 \mathrm{~s}^{-1} \cdot \mu \mathrm{M}^{-1}$ & \multirow[t]{4}{*}{ [45] } \\
\hline & 25 & 1504 & 186 & 8.08 & \\
\hline \multirow[t]{2}{*}{ Porcine } & 4 & 38 & 276 & 0.14 & \\
\hline & 25 & 394 & 87 & 4.54 & \\
\hline \multicolumn{6}{|l|}{$\alpha$-Amylase (starch) } \\
\hline \multirow[t]{2}{*}{ A. haloplanctis (Antarctic bacteria) } & 4 & $490 \mathrm{~s}^{-1}$ & $1.09 \mathrm{~g} / 1$ & $450 \mathrm{~s}^{-1} \cdot \mathrm{g}^{-1} \cdot 1$ & \multirow[t]{4}{*}[45]{} \\
\hline & 25 & 1363 & 1.27 & 1075 & \\
\hline \multirow[t]{2}{*}{ Porcine } & 4 & 71 & 1.05 & 68 & \\
\hline & 25 & 326 & 1.12 & 292 & \\
\hline \multicolumn{6}{|l|}{ Subtilisin (Suc-F-A-A-F-pNA) } \\
\hline \multirow{2}{*}{ Bacillus TA39 (Antarctic bacteria) } & 5 & $32 s^{-1}$ & $26 \mu \mathrm{M}$ & $1.2 \mathrm{~s}^{-1} \cdot \mu \mathrm{M}^{-1}$ & \multirow[t]{4}{*}{ [64] } \\
\hline & 25 & 115 & 37 & 3.2 & \\
\hline \multirow[t]{2}{*}{ Bacillus subtilis (Carlsberg) } & 5 & 18 & 6 & 3 & \\
\hline & 25 & 60 & 17 & 3.5 & \\
\hline \multicolumn{6}{|l|}{ Subtilisin (azocasein) } \\
\hline \multirow[t]{2}{*}{ Bacillus TA39 (Antarctic bacteria) } & 5 & $11 \mathrm{U} / \mathrm{mg}$ & - & - & \multirow[t]{4}{*}{ [64] } \\
\hline & 25 & 69 & - & - & \\
\hline \multirow[t]{2}{*}{ Bacillus subtilis (Carlsberg) } & 5 & 1.5 & - & - & \\
\hline & 25 & 13 & - & - & \\
\hline \multicolumn{6}{|l|}{ Xylanase (oat spelt xylane) } \\
\hline \multirow[t]{2}{*}{ Cryptococcus TAE85 (Antarctic yeast) } & 4 & $15 \mathrm{~s}^{-1}$ & $2.5 \mathrm{~g} / 1$ & $6 \mathrm{~s}^{-1} \cdot \mathrm{g}^{-1} \cdot 1$ & \multirow[t]{4}{*}{ [a] } \\
\hline & 25 & 46 & 3.8 & 12 & \\
\hline \multirow[t]{2}{*}{ Cryptococcus albidus } & 4 & 5 & 3 & 1.6 & \\
\hline & 25 & 21 & 2 & 10.5 & \\
\hline$\beta$-Lactamase (nitrocefin) & & & & & \\
\hline P. immobilis (Antarctic bacteria) & 7 & $984 \mathrm{~s}^{-1}$ & $226 \mu \mathrm{M}$ & $4.3 \mathrm{~s}^{-1} \cdot \mu \mathrm{M}^{-1}$ & [48] \\
\hline & 30 & 1407 & 51 & 27.6 & \\
\hline E. cloacae & 7 & 741 & 246 & 3.0 & \\
\hline & 30 & 942 & 65 & 14.5 & \\
\hline Other mesophiles & 30 & $330-1240$ & $12-500$ & $1-34$ & \\
\hline Trypsin (L-BAPA) & & & & & \\
\hline P. magellanica (Antarctic fish) & 5 & $29 \min ^{-1}$ & $121 \mu \mathrm{M}$ & $0.24 \min ^{-1} \cdot \mu \mathrm{M}^{-1}$ & [40] \\
\hline & 25 & 125 & 25 & 0.6 & \\
\hline Bovine & 5 & 5.4 & 170 & 0.03 & \\
\hline & 25 & 109 & 2445 & 0.04 & \\
\hline Trypsin (TAME) & & & & & \\
\hline Greenland cod & 5 & $5.2 \mathrm{U} / \mu \mathrm{M}$ & $0.14 \mathrm{mM}$ & 37 & {$[41]$} \\
\hline & 25 & 14.7 & 0.15 & 98 & \\
\hline Bovine & 5 & 1.7 & 0.05 & 35 & \\
\hline & 25 & 9.1 & 0.05 & 182 & \\
\hline Elastase (Suc-A-A-A-pNA) & & & & & \\
\hline Atlantic cod & 10 & $25 \mathrm{~s}^{-1}$ & $0.8 \mathrm{mM}$ & $31 \mathrm{~s}^{-1} \cdot \mathrm{mM}^{-1}$ & [42] \\
\hline & 25 & 44 & 1.0 & 43 & \\
\hline Pig & 10 & 12 & 0.7 & 16 & \\
\hline & 25 & 16 & 0.7 & 22 & \\
\hline Chymotrypsin (BzTyrOEt) & & & & & \\
\hline Atlantic cod (isozyme A) & 10 & $117 \mathrm{~s}^{-1}$ & $0.12 \mathrm{mM}$ & $975 \mathrm{~s}^{-1} \cdot \mathrm{mM}^{-1}$ & [43] \\
\hline & 25 & 207 & 0.14 & 1479 & \\
\hline Bovine & 10 & 43 & 0.27 & 159 & \\
\hline & 25 & 100 & 0.27 & 370 & \\
\hline
\end{tabular}

[a] Unpublished results.

state ES* is reached. Thus, decreasing the substrate binding strength contributes to lowering the activation energy and consequently to increasing the reaction rate. This principle is obviously not valid for control enzymes in metabolic pathways which operate at substrate concentrations close to $K_{m}$.

Inspection of the available data for cold-adapted enzymes (table 1) indicates that only trypsin from the Greenland cod (and possibly $\alpha$-amylase and subtilisin, but substrate specificity can interfere) seems to make use of this strategy. Other enzymes optimize $k_{\text {cat }} / K_{m}$ by decreasing $K_{m}$, increasing $k_{c a t}$ or by changes in both $k_{\text {cat }}$ and $K_{m}$. Even from this limited set of data, it appears that optimization of the catalytic parameters is reached via various ways. As mentioned above, the main drawback of the current analysis is to determine the key parameter(s) that have to be optimized. In fact, no general rule is to be expected, taking into account the 


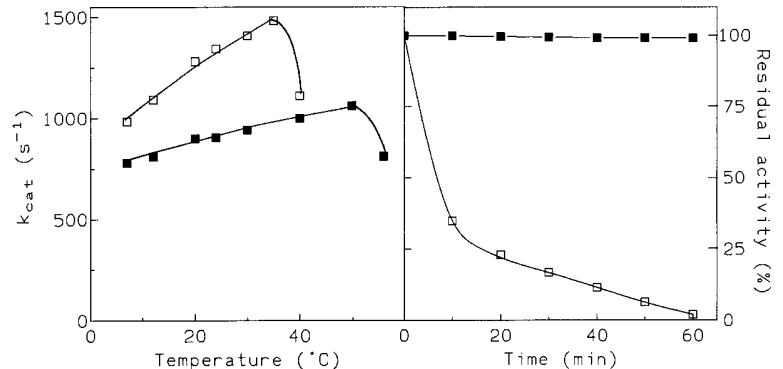

Figure 4. Activity and stability of $\beta$-lactamases from the psychrophile Psychrobacter immobilis $(\square)$ and the mesophile Enterobacter cloacae ( $\mathbf{\square})$. Left panel: temperature dependence of $k_{\text {cat }}$ for the hydrolysis of nitrocefin. Right panel: residual activity after incubation at $50{ }^{\circ} \mathrm{C}$

various physiological states of enzymes (secreted, membrane-embeded, linked to a pathway etc.) and the nature, solubility or availability of substrates. It is also quite possible that our concept of catalytic effectiveness remains imperfect and may require more sophisticated models as those developed by Knowles and coworkers [47]. The peculiar case of the class $\mathrm{C} \beta$-lactamase (cephalosporinase) from Psychrobacter immobilis also deserves some comments because the specific activity of this antibiotic-degrading enzyme at low temperatures is not favoured when compared to $\beta$-lactamases from mesophilic pathogenic bacteria (fig. 4). To explain this unusual observation, we have argued elsewhere [48] that the mesophilic pathogenes are themselves extremophilic microorganisms (they have evolved under the strong selective pressure of clinical antibiotics) and also that antibiotic concentration in the Antarctic environment is certainly very low. However, another element has to be taken into consideration. Indeed, class $C \beta$-lactamases

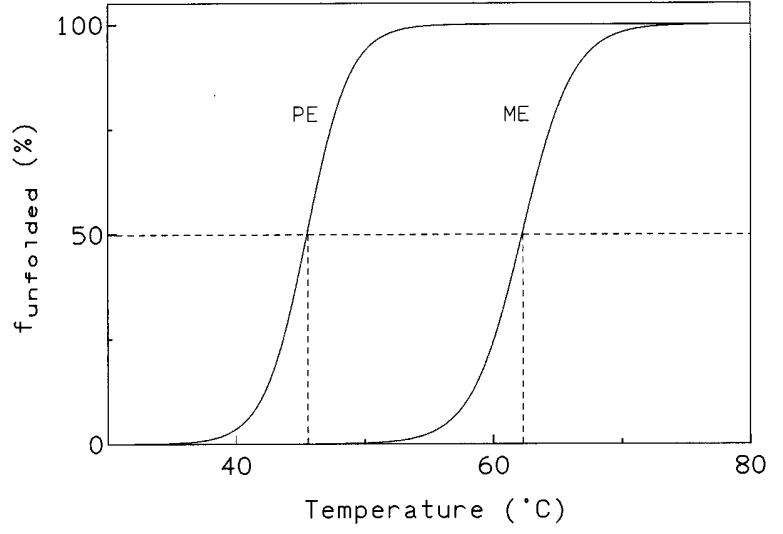

Figure 5. Heat-induced unfolding of psychrophilic (PE) and mesophilic (ME) enzymes (here $\alpha$-amylases). The melting point $\mathrm{Tm}$ is the midpoint of the thermal unfolding curve where $\Delta G=0$. The difference in melting point values $(\Delta \mathrm{Tm})$ usually ranges between 15 and $20{ }^{\circ} \mathrm{C}$.

have almost diffusion-controlled reaction rates [46, 49]. As a result, activity of both mesophilic and psychrophilic cephalosporinases is weakly influenced by temperature with $\mathrm{Q}_{10}$ as low as 1.1 (fig. 4). Such perfectly evolved enzymes have therefore very few possibilities to further improve $k_{\text {cat }}$ values in the context of cold adaptation. But the most interesting point revealed by the psychrophilic cephalosporinase is the persistence of the low stability (fig. 4). This raises another question: if the psychrophilic cephalosporinase is almost perfectly evolved, why should it be thermolabile? Is it the result of the lack of selective pressure for a stable protein, or is heat-lability a common property required for efficient catalysis at low temperatures? As explained in the next paragraphs, the latter proposition seems to apply here.

Table 2. Thermodynamic activation parameters of some psychrophilic hydrolases and of their mesophilic or homeothermic homologues.

\begin{tabular}{|c|c|c|c|c|c|c|c|}
\hline Enzyme & $\begin{array}{l}\mathrm{T} \\
0^{\circ} \mathrm{C}\end{array}$ & $\begin{array}{l}k_{\text {cat }} \\
\mathrm{s}^{-1}\end{array}$ & $\begin{array}{l}E a^{\mathrm{a}} \\
\mathrm{kJ} \cdot \mathrm{mol}^{-1}\end{array}$ & $\begin{array}{l}\Delta G^{*} \\
\mathrm{~kJ} \cdot \mathrm{mol}^{-1}\end{array}$ & $\begin{array}{l}\Delta H^{*} \\
\mathrm{~kJ} \cdot \mathrm{mol}^{-1}\end{array}$ & $\begin{array}{l}\Delta S^{*} \\
\mathrm{~J} \cdot \mathrm{mol}^{-1} \cdot \mathrm{K}\end{array}$ & ref. \\
\hline \multicolumn{8}{|l|}{$\alpha$-Amylase } \\
\hline A. haloplanctis (psychro.) & 15 & 187 & 73 & 58 & 71 & 46 & [44] \\
\hline B. amyloliquefaciens & 15 & 34 & 99 & 62 & 97 & 122 & \\
\hline \multicolumn{8}{|l|}{ Subtilisin } \\
\hline Bacillus TA41 (psychro.) & 15 & 25 & 38 & 62 & 36 & -92 & [59] \\
\hline Bacillus subtilis & 15 & 5 & 48 & 66 & 46 & -70 & \\
\hline \multicolumn{8}{|l|}{ Trypsin } \\
\hline Greenland cod & 25 & $0.21^{\mathrm{b}}$ & 28 & 53 & 32 & $-70^{\mathrm{c}}$ & [41] \\
\hline Bovine & 25 & 0.03 & 53 & 60 & 53 & -25 & \\
\hline
\end{tabular}

${ }^{\mathrm{a}}$ Ea-Arrhenius activation energy.

${ }^{\mathrm{b}} \mathrm{Units} / \mu \mathrm{M}$

${ }^{c}$ Entropy unit not defined by authors. 


\section{The active site of psychrophilic enzymes}

Although only one crystal structure from a psychrophilic enzyme is available ([50], N. Aghajari and R. Haser, personal communication) in addition to the salmon trypsin [51] and elastase [52] structures, molecular modelling was extremely useful for preliminary structural analyses of cold-adapted enzymes. Structure prediction by homology modelling has recently reached sufficient level of reliability [53, 54] to allow close inspection of the psychrophilic enzyme conformation, keeping in mind the limit of confidence of such models. The active site of psychrophilic enzymes was subjected to careful examination. It was noted that all amino acid residues involved in the reaction mechanism, as well as all side chains pointing towards the catalytic cavity, are strictly conserved with respect to their mesophilic homologues. This observation is not really surprising because the reaction pathway and the specificity of a given psychrophilic enzyme are not prone to drastic variation, except for the improved reaction rate. Furthermore, the structure of the complex of a mesophilic $\alpha$-amylase with a pseudosaccharide inhibitor mimicking a transition state intermediate has been determined at $2.2 \AA$ resolution [55]. Comparison of residues having direct or even water-mediated H-bonds to the inhibitor shows that all 24 residues involved are strictly conserved in the psychrophilic enzyme. This outstanding example of active site identity demonstrates that the specific properties of the cold-adapted enzyme can be reached without any amino acid substitution in the catalytic centre or the major substrate binding site. It is therefore assumed that changes in primary structure that occur distantly from the active site could be responsible for the optimization of the catalytic parameters.

\section{Flexibility-activity relationship}

Up to now, a correlation between conformational flexibility and enzyme activity is the most widely accepted hypothesis accounting for the dominant adaptative traits of psychrophilic enzymes, i.e. their high activity and their weak stability. This concept, previously proposed for ectothermic species [11, 14], is based on the observation that thermal stabilities of enzymes homologues are almost invariably correlated positively with environmental temperature. Clearly, selection does not favour the most stable enzyme structure, despite the relative ease with which proteins can be stabilized by minor changes of their primary structure. The current view of protein molecular dynamics [46] suggests that enzyme structure must achieve a balance between stability (allowing the retention of a specific 3D conformation at the physiological temperature) and flexibility (allowing the protein to perform its catalytic function).
In this context, a highly flexible structure of psychrophilic enzymes can provide enhanced ability to undergo discrete and fast conformational changes at low temperatures imposed by the catalytic events. This concept is subordinated to at least two other hypotheses which are not yet definitively established and which will be one of the main goals in future work in this field: i) does the weak stability of psychrophilic enzymes truly reflects an improved conformational flexibility? ii) does the expected conformational flexibility favour a high enzymatic activity at low temperatures?

The low stability of all psychrophilic enzymes investigated so far has been well demonstrated by the drastic shift of the apparent optimal temperature of activity, by the low resistance to protein denaturants, and by the susceptibility of secondary structures to unfolding at moderate temperatures [11, 14, 44, 56]. Circular dichroism spectra of psychrophilic and mesophilic $\alpha$-amylases also suggested that the conformation of the cold-adapted enzyme was less compact at all temperatures used. In addition, both enzymes seemed to possess the same conformation at their physiological temperature [44]. The difference in conformational stability $\left(\Delta G_{\mathrm{N}-\mathrm{D}}\right)$ between psychrophilic and mesophilic $\alpha$-amylases has been estimated to $30 \mathrm{~kJ} \cdot \mathrm{mol}^{-1}$ using heat-induced unfolding curves recorded by fluorescence (fig. 5). Similar or slightly lower values have been recorded between mesophilic and thermophilic enzymes [57]. If the weak stability is indeed a key parameter of cold-adaptation, we could anticipate that these heat-labile proteins will serve as perfect tools for fundamental studies in the field of protein folding because they represent the lower natural limit of polypeptidic conformational stability.

Intuitively, we can easily relate the stability of a protein to its conformational flexibility. In the specific case of psychrophilic enzymes, there is however no direct experimental demonstration of such relationship. The crystallographic $B$-temperature factors (which are a function of individual atom mobility) of the recently crystallized $\alpha$-amylase from the Antarctic psychrophile A. haloplanctis (N. Aghajari and R. Haser, personal communication) and of trypsin from the cold-adapted North Atlantic salmon [51] fail to reveal significant difference when compared with X-ray structures of mesophilic homologues. However, constraints imposed by the crystal packing of the molecules and intermolecular contacts can obscure possible differences occurring in solution. Preliminary hydrogen/deuterium exchange rate measurements recorded by FTIR (Fourier transform infrared spectroscopy) carried out with psychrophilic and mesophilic $\alpha$-amylases also failed to reveal any significant difference in the rate and magnitude of amide proton replacement. Surface loops are more susceptible to H/D exchanges: because the psychrophilic enzyme has shorter external loops, the lower 
bulk of exchangeable protons can possibly compensate for an improved $H / D$ exchange due to flexibility. In addition, molecular dynamics simulation of salmon and bovine trypsins has indicated that the overall dynamic properties of both enzymes are similar [58]. Strictly speaking, the fish enzyme is not more flexible, but clear differences in the mobility of particular regions were observed, suggesting that only discrete structures may be responsible for the global dynamic properties. We can expect that NMR experiments using small psychrophilic proteins will give a better insight into the expected stability-flexibility relationship.

Some groups are currently probing the flexibility-activity relationship using genetically engineered psychrophilic enzymes. For instance, weak interactions mediated by residues occurring in mesophilic or thermophilic enzymes are being introduced in psychrophilic enzymes specifically devoid of these interactions. The main goal of these site-directed mutagenesis experiments is to stabilize the psychrophilic mutants and to record the changes of the specific activity associated with the mutation.

\section{Structural factors affecting the stability of psychrophilic enzymes}

In addition to the above mentioned crystal structures [50, 51, 52] models of psychrophilic enzymes such as bacterial subtilisin [59], $\alpha$-amylase [45], triosephosphate isomerase [60], lipase [61], $\beta$-lactamase [48] or fish trypsin [62] and elastase [63] reveal that only subtle modifications of their conformation can be related to the low stability (see also [64, 65]). Electrostatic weak interactions and the hydrophobic effect make a lower contribution to the global energy of stabilization of the native state whereas destabilizing forces mainly favour the conformational entropy of the unfolded state. The net result of the altered structural contributions observed is to drive the $\mathrm{N} \rightleftharpoons \mathrm{D}$ equilibrium forward and to reduce the melting temperature $\operatorname{Tm}$ (at which $\Delta G_{\mathrm{N}-\mathrm{D}}$ $=0)$ as well as the conformational stability $\Delta G_{\mathrm{N}-\mathrm{D}}$.

Ion pairs and arginine residues. Among electrostatic weak interactions, ions pairs between two opposite side chain charges are the strongest stabilizing factors of protein conformation. When compared with mesophilic homologues, several psychrophilic enzymes lack surface salt bridges or ion pairs bonding secondary structures and protein domains [45, 59]. Arginine residues also play a significant role in thermal adaptation. Indeed, the charge resonance of the guanidinium group gives arginine the possibility to form more than one salt bridge. For instance, Arg-mediated networks of ion pairs appear to be responsible for the unusual stability of glutamate dehydrogenase from the hyperthermophilic archaeon Pyrococcus furiosus [66]. In addition, the arginine side chain can form up to five H-bonds, preferably to carbonyl oxygens [67]. Both structural properties of arginine certainly account for its low occurrence in psychrophilic enzymes as indicated by the Arg molar ratio or by the Arg/(Arg + Lys) ratio.

H-bonding pattern. The individual contribution of $\mathrm{H}$ bonds to protein stability is weak but the large number of these interactions in protein structures makes them a predominant factor of the folded state conformation [68]. The crystal structures of salmon and bovine trypsins [51] provided evidence that the disappearance of several H-bonds in the cold-adapted enzyme is responsible for loose contacts between the two $\beta$-barrel domains of the protein close to the catalytic residues, and between the C-terminal helix and the $\mathrm{N}$-terminal domain. The total number of polar hydrogen-forming residues (Ser, Thr, Asn and Gln) is also lower in digestive enzymes from cold-adapted fish [69, 70].

Aromatic interactions. Weakly polar interactions mediated by the aromatic ring of Tyr, Phe and Trp are of an enthalpic importance comparable to that of a hydrogen bond [71]. Several aromatic interactions between strongly conserved aromatic residues in mesophilic subtilisins or $\beta$-lactamases are missing in their psychrophilic homologues, suggesting that these altered interactions contribute to the low stability.

Charge-dipole interactions in $\boldsymbol{\alpha}$-helices. Electrostatic interactions of the $\alpha$-helix dipole with an opposite side chain charge at the $\mathrm{N}$ - or $\mathrm{C}$-cap of the helix stablilizes the secondary structure [72]. Such interactions appear especially important in the conformation of a psychrophilic triosephosphate isomerase which is composed of a $(\beta / \alpha)_{8}$ barrel. Indeed, unfavourable charge-dipole interactions are thought to destabilize several helices of the barrel [60].

Ion binding. Metal ion binding, frequently calcium ions, can provide extra stability incomparably superior to any other weak interaction and even higher than a disulphide bond. In the case of $\mathrm{Ca}^{2+}$, this is certainly related to the eight or nine possible coordination bonds that are able to bridge several secondary structures or domains of a protein. All $\mathrm{Ca}^{2+}$-binding psychrophilic proteins investigated so far are characterized by low binding constants. In subtilisin, the low affinity seems to arise from the replacement of a strongly conserved polar ligand (Asn in mesophiles or thermophiles) by a threonine and the stacking of Gly residues around this ligand [59]. On the other hand, residues forming the calcium binding site of a psychrophilic $\alpha$-amylase are identical to those of the mesophilic homologues: here, the low affinity for $\mathrm{Ca}^{2+}$ probably results from the flexible structure of the cold-adapted enzyme [45].

Solvent interactions. Protein unfolding occurs when the balance of forces between the internal interactions and the interactions with its environment is disrupted. Therefore, destabilization can originate from an in- 
crease in the number of interactions between water and the molecule in such a way that water molecules compete for the internal H-bonds of the protein [73]. The recurrent observation of very hydrophilic surfaces in psychrophilic enzymes, sometimes leading to abnormal pI, suggests that improved solvent interactions can reduce the compactness of the protein's external shell [48, 59, 62].

Hydrophobic effect. The clustering of hydrophobic side chains within the protein core is a major driving force in the stability of the folded conformation [74]. Attempts to evaluate this effect on the basis of structure have been performed, using the hydrophobic index of individual amino acids forming the protein core, or using hydrophobic cluster analysis. Numerous psychrophilic enzymes display substitutions within the hydrophobic core clusters that are accompanied by a sharp decrease of the hydrophobicity index when compared with mesophilic homologues [45, 48, 51, 62].

Entropic factors. Disulphide bonds and proline residues reduce the conformational degree of freedom of an unfolded polypeptide. There is no evidence from the available data that psychrophilic enzymes avoid disulphide bonds in order to gain flexibility, probably because of the stringent steric constraints imposed by the S-S linkage. By contrast, proline avoidance in loops and turns connecting secondary structures has been noted in almost all investigated psychrophilic enzymes. The glycine content of cold-adapted proteins is not different from mesophilic proteins but stacking of Gly residues close to functional domains is thought to contribute to the local flexibility: glycine has no side chain and provides dihedral angles not allowed by most other residues. Typical examples are the $\mathrm{Ca}^{2+}$-binding site of subtilisin [59] and the active site of lipases [75]. A similar role of methionine has been proposed to account for the increased Met molar ratio of serine proteases from cold-adapted fish [69].

$\mathbf{N}$ - and C-termini. Protein extremities are preferential sites for the initiation of unfolding if they are not buried within the structure or constrained by weak interactions. The $\mathrm{C}$-terminal end of $A$. haloplanctis $\alpha$-amylase is longer than that of its mesophilic homologues and freely swims in the solvent. The $\mathrm{N}$-terminal $\alpha$-helix of $P$. immobilis $\beta$-lactamase [48] and the C-terminal helix of salmon trypsin [51] are also less firmly maintained at the surface of the molecule. These examples indicate that loose or relaxed extremities could be involved in the overall weak thermal stability.

Indels. Insertions or deletions (indels) in the primary structure are frequently responsible for the acquisition of specific properties. For instance, the low stability of the psychrophilic subtilisin was tentatively correlated with the occurrence of several long surface loops which improve interactions with the solvent and lower the compactness of the molecular surface [59]. In the case of elastase from the Antarctic fish $N$. neglecta, a small deletion make the entrance of the catalytic cavity markedly more accessible, possibly allowing easier substrate accommodation [63]. Two small insertions in loops involved in dimerization of Moraxella triosephosphate isomerase were also expected to favour dimer destabilization [60]. The latter observation reinforces the idea that forces maintaining contacts between monomers have to be taken into account in future analysis of polymeric cold-adapted enzymes.

\section{The point mutation hypothesis}

Protein engineers are well aware that even a single substitution can drastically modify enzyme activity and stability, either positively or negatively. Thus, natural selection can theoretically make use of a discrete mutation to render a given protein suitable for psychrophilic living conditions. This is obviously not the general situation: available structural data from enzymes adapted to extreme environments rather suggest that many weak interactions are modified in order to adapt the molecular dynamics. There are emerging insights, however, that a single amino acid substitution could be responsible for almost all the psychrophilic character of some cold-adapted enzymes. In the case of closely related fish $\mathrm{LDH}$ differing in temperature- $K_{m}$ relationships or stability, only a single difference in sequence was detected at a subunit contact site [14]. In addition, a preliminary report of site-directed mutagenesis experiment in Vibrio marinus triosephosphate isomerase clearly indicates that replacement of a completely conserved Ser in the phosphate binding helix by Ala in the psychrophilic enzyme accounts for nearly all the improvement in catalytic efficiency [76].

\section{Conclusions}

The main lesson from a survey of the adaptative traits of psychrophilic enzymes is certainly the vast array of strategies encountered in order to reach an unique goal: to improve the catalytic efficiency at low temperatures and possibly to gain conformational flexibility. Optimization of the catalytic parameters is reached via fine adjustments of $k_{c a t}, K_{m}$ or both, according to the conditions imposed by the physiological environment of these enzymes. As a consequence, no common strategy emerges when comparing intracellular or extracellular proteins from prokaryotic or eukaryotic organisms. At the molecular level, the determinants of the expected conformational flexibility range from a single mutation in a functional site (not the active site) to a large number of altered weak interactions distributed in the whole structure. All known structural factors and weak interactions involved in protein stability are either re- 
duced in number or modified in psychrophilic enzymes in order to increase their flexibility. No general rules govern this adaptation: each enzyme adopts its own stategy by using one or a combination of these altered interactions. The same structural factors have been implicated in the stability of thermophilic proteins, which indicates that there is a continuum in the strategy of protein adaptation to temperature. This is in agreement with the proposed interdependence of stability, flexibility and activity, allowing extremophilic enzymes to preserve the integrity of their conformation with sufficient plasticity to perform catalysis at extreme temperatures.

Acknowledgments. This work has been supported by the E.U. under the form of the network contract ERBCHCT 940521, the concerted action BIO4-CT95-0017 and the Biotech programm BIO4-CT96-0051, by the Ministère de l'Education, de la Recherche et de la Formation, concerted action ARC93/98-170 and by the Région Wallonne-Direction Générale des Technologies, convention 1828. We thank N. Aghajari and R. Haser for providing access to the crystal structure coordinates of the psychrophilic amylase. We also thank the Institut Français de Recherche et de Technologie Polaire for generously accomodating our research fellows at the French Antarctic Station J.S. Dumont d'Urville in Terre Adélie.

1 Raymond J. A., Wilson P. and DeVries A. L. (1989) Inhibition of growth of non-basal planes in ice by fish antifreezes. Proc. Natl Acad. Sci. USA 86: $881-885$

2 Jia Z., DeLuca C. I. Chao H. and Davies P. L. (1996) Structural basis for the binding of a globular antifreeze protein to ice. Nature 384: $285-288$

3 Duman J. G. and Olsen T. M. (1993) Thermal hysteresis protein activity in bacteria, fungi and phylogenetically diverse plants. Cryobiology 30: $322-328$

4 Sun X., Griffith M., Pasternak J. J. and Glick B. (1995) Low temperature growth, freezing survival and production of antifreeze protein by the plant growth promoting rhizobacterium Pseudomonas putida GR12-2. Can. J. Microbiol. 41: 776-784

5 Duman J. G., Wu D. W., Xu L., Tursman D. and Olsen T. M. (1991) Adaptations of insects to subzero temperatures. Quant. Rev. Biol. 66: $387-410$

6 Franks F. (1985) Biophysics and biochemistry at low temperatures. Cambridge University Press, Cambridge

7 Russell N. J. (1990) Cold adaptation of microorganisms. Phil. Trans. R. Soc. London. B326: 595-611

8 Russell N. J. (1992) Physiology and molecular biology of psychrophilic microorganisms. In: Molecular Biology and Biotechnology of Extremophiles, Herbert R. A. and Sharp R. J. (eds), pp. 203-224, Blackie, London

9 Friedmann E. I. (1982) Endolithic microorganisms in the antarctic cold desert. Science 215: 1045-1053

10 Hazel J. R. and Prosser C. L. (1974) Molecular mechanisms of temperature compensation in poikilotherms. Biol. Rev. 54: 620-677

11 Hochachka P. W. and Somero G. N. (1984) Biochemical Adaptations, Princeton University Press, Princeton

12 Storey K. B. and Storey J. M. (1988) Freeze tolerance in animals. Physiol. Rev. 68: $27-84$

13 Jaenicke R. (1990) Proteins at low temperature. Phil. Trans. R. Soc. Lond. B326: $535-553$

14 Somero G. N. (1995) Proteins and temperature. Annu. Rev. Physiol. 57: 43-68

15 Jones P. G. and Inouye M. (1994) The cold shock response-a hot topic. Mol. Microbiol. 11: 811-818

16 Ray M. K., Sitaramamma T., Ghandi S. and Shivagi S. (1994) Occurence and expression of CspA, a cold shock gene in antarctic psychrotrophic bacteria. FEMS Microbiol. Lett. 116: $55-60$

17 Hebrand M., Dubois E., Potier P. and Labadie J. (1994) Effect of growth temperatures on the protein levels in a psychrotrophic bacterium Pseudomonas fragi. J. Bacteriol. 176: $4017-$ 4024

18 Mayr B., Kaplan T., Lechner S. and Scherer S. (1996) Identification and purification of a family of dimeric major cold shock protein homologs from the psychrotrophic Bacillus cereus WSB 10201. J. Bacteriol. 178: 2916-2925

19 Berger F., Morellet N., Menu F. and Potier P. (1996) Cold shock and cold acclimation proteins in the psychrotrophic bacterium Arthrobacter blobiformis SI55. J. Bacteriol. 178: 2999-3007

20 Tanner J. J., Hecht R. M. and Krause K. L. (1996) Determinants of enzyme thermostability observed in the molecular structure of Thermus aquaticus D-glyceraldehyde-3-phosphate dehydrogenase at $2.5 \AA$ resolution. Biochemistry 35: 2597-2609

21 Morita R. Y. (1975) Psychrophilic bacteria. Bacteriol. Rev. 39: 144-167

22 Hohman R. W. (1975) Optimum temperatures and temperature ranges for growth of snow algae. Arctic Alpine Res. 7: $13-24$

23 Loppes R., Devos N., Willem S., Barthélemy P. and Matagne R. F. (1996) Effect of temperature on two enzymes from a psychrophilic Chloromonas (Chlorophyta). J. Phycol. 32: 276278

24 Lee R. E. and Denlinger D. L. (1991) Insects at low temperatures, Chapman and Hall, New York

25 Eastman J. T. (1993) Antarctic fish biology, evolution in a unique environment, Academic Press, San Diego

26 Feller G., Narinx E., Arpigny J. L., Zekhnini Z., Swings J. and Gerday C. (1994) Temperature dependence of growth, enzyme secretion and activity of psychrophilic antarctic bacteria. Appl. Microbiol. Biotechnol. 41: 477-479

27 Ruger H. J. (1988) Substrate dependent cold adaptations in some deep-sea sediment bacteria. System. Appl. Microbiol. 11: 90-93

28 Wiebe W. J., Sheldon W. M. and Pomeroy L. R. (1992) Bacterial growth in the cold: evidence for an enhanced substrate requirement. Appl. Environ. Microbiol. 58: 359-364

29 Orange N. (1994) Growth temperature regulates the induction of $\beta$-lactamase in Pseudomonas fluorescens through modification of the outer membrane permeation of a $\beta$-lactam inducing antibiotic. Microbiology 140: $3125-3130$

30 Guillou C., Merieau A., Trebert B. and Guespin-Michel J. F. (1995) Growth temperature is involved in the regulation of extracellular lipase at two different levels in Pseudomonas fluorescens strain MF0. Biotechnol. Lett. 17: 377-382

31 Guillou C. and Guespin-Michel J. F. (1995) Evidence for two domains of temperature for the psychrotrophic bacterium Pseudomonas fluorescens MF0. Appl. Environ. Microbiol. 62: $3319-3324$

32 De E., Orange N., Saint N., Guerillon J., De Mot R. and Molle G. (1997) Growth temperature dependence of channel size of the major outer membrane protein (Oprf) in psychrotrophic Pseudomonas fluorescens strains. Microbiology 143: 1029-1035

33 Sterner R., Kleemann G. R., Szadkowski H., Lustig A., Hennig M. and Kirschner K. (1996) Phosphoribosyl anthranilate isomerase from Thermotoga maritima is an extremely stable and active homodimer. Protein Sci. 5: 2000-2008

34 Low P. S., Bada J. L. and Somero G. N. (1973) Temperature adaptations of enzymes: roles of the free energy, the enthalpy and the entropy of activation. Proc. Natl Acad. Sci. USA 70: $430-432$

35 Londesborough J. (1980) The causes of sharply bent or discontinuous Arrhenius plots for enzyme-catalysed reactions. Eur. J. Biochem. 105: 211-215

36 Clarke A. (1983) Life in cold water: the physiological ecology of polar marine ectotherms. Oceanogr. Mar. Biol. Annu. Rev. 21: $341-453$ 
37 Mohr P. W. and Krawiec S. (1980) Temperature characteristics and Arrhenius plots for nominal psychrophiles, mesophiles and thermophiles. J. Gen. Microbiol. 121: $311-317$

38 Crawford D. L. and Powers D. A. (1989) Molecular basis of evolutionary adaptation at the lactate dehydrogenase-B locus in the fish Fundulus heteroclitus. Proc. Natl Acad. Sci. USA 86: 9365-9369

39 Crawford D. L. and Powers D. A. (1992) Evolutionary adaptation to different thermal environments via transcriptional regulation. Mol. Biol. Evol. 9: 806-813

40 Genicot S., Feller G. and Gerday C. (1988) Trypsin from antarctic fish (Paranotothenia magellanica Forster) as compared with trout (Salmo gairdneri) trypsin. Comp. Biochem. Physiol. 90B: 601-609

41 Simpson B. K. and Haard N. F. (1984) Purification and characterization of trypsin from the Greenland cod (Gadus ogac). 1. Kinetic and thermodynamic characteristics. Can. J. Biochem. Cell. Biol. 62: 894-900

42 Asgeirsson B. and Bjarnason J. B. (1993) Properties of elastase from Atlantic cod, a cold-adapted proteinase. Biochim. Biophys. Acta 1164: $91-100$

43 Asgeirsson B. and Bjarnason J. B. (1991) Structural and kinetic properties of chymotrypsin from atlantic cod (Gadus morhua). Comparison with bovine chymotrypsin. Comp. Biochem. Physiol. 99B: 327-335

44 Feller G., Lonhienne T., Deroanne C., Libioulle C., Van Beeumen J. and Gerday C. (1992) Purification, characterization, and nucleotide sequence of the thermolabile a-amylase from the antarctic psychrotroph Alteromonas haloplanctis A23. J. Biol. Chem. 267: 5217-5221

45 Feller G., Payan F., Theys F., Qian M., Haser R. and Gerday C. (1994) Stability and structural analysis of a-amylase from the antarctic psychrophile Alteromonas haloplanctis A23. Eur. J. Biochem. 222: 441-447

46 Fersht A. (1985) Enzyme structure and mechanism. W.H. Freeman and Company, New York

47 Burbaum J. J., Raines R. T., Albery W. J. and Knowles J. R. (1989) Evolutionary optimization of the catalytic effectiveness of an enzyme. Biochemistry 28: 9293-9305

48 Feller G., Zekhnini Z., Lamotte-Brasseur J. and Gerday C. (1997) Enzymes from cold-adapted microorganisms. The class C $\beta$-lactamase from the antarctic psychrophile Psychrobacter immobilis A5. Eur. J. Biochem. 244: 186-191

49 Fisher J., Belasco J. G., Khosla S. and Knowles J. R. (1980) $\beta$-lactamase proceeds via an acyl-enzyme intermediate. Interaction of the Escherichia coli RTEM enzyme with cefoxitin. Biochemistry 19: 2895-2901

50 Aghajari N., Feller G., Gerday C. and Haser R. (1996) Crystallization and preliminary X-ray diffraction studies of $\alpha$-amylase from the antarctic psychrophile Alteromonas haloplanctis A23. Protein Sci. 5: 2128-2129

51 Smalas A. O., Heimstad E. S., Hordvik A., Willassen N. P. and Male R. (1994) Cold adaptation of enzymes: structural comparison between salmon and bovine trypsins. Proteins: Struct. Funct. Genet. 20: $149-166$

52 Berglund G. I., Willassen N. P., Hordvik A. and Smalas A. O. (1995) Structure of native pancreatic elastase from North Atlantic salmon at $1.61 \AA ̊$ resolution. Acta Cryst. D51: $925-$ 937

53 Mosimann S., Meleshko R. and James M. N. G. (1995) A critical assessment of comparative molecular modeling of tertiary structures of proteins. Proteins Stuct. Funct. Genet. 23: $301-317$

54 Sali A. (1995) Modelling mutations and homologous proteins. Curr. Opin. Biotechnol. 6: 437-451

55 Qian M., Haser R., Buisson G., Duée E. and Payan F. (1994) The active center of a mammalian a-amylase with a carbohydrate inhibitor refined to $2.2 \AA$ resolution. Biochemistry 33: 6284-6294

56 Kobori H., Sullivan C. W. and Shizuya H. (1984) Heat-labile alkaline phosphatase from antarctic bacteria: rapid $5^{\prime}$ endlabelling of nucleic acids. Proc. Natl Acad. Sci. USA 81: $6691-6695$
57 Perutz M. F. and Raidt H. (1975) Stereochemical basis of heat stability in bacterial ferredoxins and in haemoglobin A2. Nature 255: 256-259

58 Heimstad E. S., Hansen L. K. and Smalas A. O. (1995) Comparative molecular dynamics simulation studies of salmon and bovine trypsins in aqueous solution. Protein Eng. 8: $379-388$

59 Davail S., Feller G., Narinx E. and Gerday C. (1994) Cold adaptation of proteins. Purification, characterization and sequence of the heat-labile ubtilisin from the antarctic psychrophile Bacillus TA41. J. Biol. Chem. 269: 17448-17453

60 Rentier-Delrue F., Mande S. C., Moyens S., Terpstra P., Mainfroid V., Goraj K. et al. (1993) Cloning and overexpression of the triosephosphate isomerase genes from psychrophilic and thermophilic bacteria. J. Mol. Biol. 229: 85-93

61 Arpigny J. L., Lamotte J. and Gerday C. (1997) Molecular adaptation to cold of an antarctic bacterial lipase. J. Mol. Catal. B(3): $29-35$

62 Genicot S., Rentier-Delrue F., Edwards D., VanBeeumen J. and Gerday C. (1996) Trypsin and trypsinogen from antarctic fish: molecular basis of cold adaptation. Biochim. Biophys. Acta 1298: $45-57$

63 Aittaleb M., Hubner R., Lamotte-Brasseur J. and Gerday C. (1997) Cold adaptation parameters derived from cDNA sequencing and molecular modelling of elastase from antarctic fish Notothenia neglecta. Protein Eng. 10: 475-477

64 Feller G., Narinx E., Arpigny J. L., Aittaleb M., Baise E., Genicot S. et al. (1996) Enzymes from psychrophilic organisms. FEMS Microbiol. Rev. 18: 189-202

65 Feller G., Arpigny J. L., Narinx, E. and Gerday C. (1997) Molecular adaptations of enzymes from psychrophilic organisms. Comp. Biochem. Physiol. 118A: (in press)

66 Yip K. S. P., Stillman T. J., Britton K. L., Artymiuk P. J., Baker P. J., Sedelnikova S. E. et al. (1995) The structure of Pyrococcus furiosus glutamate dehydrogenase reveals a key role for ion-pair networks in maintaining enzyme stability at extreme temperatures. Structure 3: 1147-1158

67 Borders C. L., Broadwater J. A., Bekeny P. A., Salmon J. A., Lee A. S., Eldridge A. M. et al. (1994) A structural role for arginine in proteins: multiple hydrogen bonds to backbone carbonyl oxygens. Protein Sci. 3: $541-548$

68 Creighton T. E. (1991) Stability of folded conformations. Curr. Opin. Struct. Biol. 1: 5-16

69 Gudmundsdottir E., Spilliaert R., Yang Q., Craik C. S., Bjarnason J. B. and Gudmundsdottir A. (1996) Isolation and characterization of two cDNAs from atlantic cod encoding two distinct psychrophilic elastases. Comp. Biochem. Physiol. 113B: $795-801$

70 Gudmundsdottir A., Oskarsson S., Eakin A. E., Craik C. S. and Bjarnason J. B. (1994) Atlantic cod cDNA encoding a psychrophilic chymotrypsinogen. Biochim. Biophys. Acta 1219: $211-214$

71 Burley S. K. and Petsko G. A. (1988) Weakly polar interactions in proteins. Adv. Protein Chem. 39: 125-189

72 Shoemaker K. R., Kim P. S., York E. J., Stewart J. M. and Baldwin R.L. (1987) Tests of the helix dipole model for the stabilisation of $\alpha$-helices. Nature 326: $563-567$

73 Schiffer C. A. and Dötsch V. (1996) The role of protein-solvent interactions in protein unfolding. Curr. Opin. Biotechnol. 7: $428-432$

74 Privalov P. L. and Gill S. J. (1988) Stability of protein structure and hydrophobic interaction. Adv. Protein Chem. 39: $191-234$

75 Feller G., Thiry M. and Gerday C. (1991) Nucleotide sequence of the lipase gene lip2 from the antarctic psychrotroph Moraxella TA144 and site-specific mutagenesis of the conserved serine and histidine residues. DNA Cell Biol. 10: $381-$ 388

76 Alvarez M., Rentier-Delrue F., Goraj K. and Mainfroid V. (1997) Vibrio marinus TIM: a cold adapted enzyme. Arch. Physiol. Biochem. 105: B17-B42 